\title{
Perception vs Reality 3D Body Image, Self-Esteem and Vanity Sizing
}

\author{
Marie-Ève FAUST ${ }^{* 1}$, Isabelle LESSARD ${ }^{2}$, Marie-Ève BLACKBURN ${ }^{3,4}$ \\ ${ }^{1}$ Philadelphia University, Fashion Merchandising Management, \\ School of Business Administration, Philadelphia, PA, USA; \\ ${ }^{2}$ Vestechpro, Apparel Research and Innovation Center, Montréal, QC, Canada; \\ ${ }^{3}$ ÉCOBES - Recherche et transfert at Cégep de Jonquière, Jonquière, QC, Canada; \\ ${ }^{4}$ Département des sciences de la santé, Université du Québec à Chicoutimi, Chicoutimi, QC, Canada
}

http://dx.doi.org/10.15221/14.269

\begin{abstract}
Purpose: Many studies have been conducted since the arrival of the 3D body scanner measuring body sizes and looking at shapes either for national sizing campaigns, or specific target markets, or simply to learn about particular parts such as head or foot. Very little has yet focused on the perception of oneself and its definite $3 \mathrm{D}$ image, thus about vanity.

The purpose of this research is to investigate how people perceived themselves, compared to their 3D image. This research also parallel participants' self-esteem [vanity/ body cathexis] with their understanding [appreciation] of apparel sizing.
\end{abstract}

Design/methodology/approach: To achieve our objectives, our main method, is to survey participants at the Montreal 2014 Fashion \& Design Festival. Participants are ask to: (i) complete a threefold questionnaire and (ii) to voluntary be scanned. The first section of the questionnaire measures global self-worth [own perception and self-esteem] of individuals with an existing and tested 10-item scale found in the literature. The second section measure participants' perception towards vanity sizing. Questions were elaborated based on literature statement. Lastly the third section compiles participants' demographic data.

After completing the questionnaire, participants are scanned using a 3D body scanner (NX16) from $[\mathrm{TC}]^{2}$. Participants receive initiatives to participating in the survey and a copy of their 3D image.

Findings: According to our pilot test, results validate that self-esteem is link with (dis)satisfaction of ones' appearance, the visible aspect of a person, but not necessary to its "3D depiction". Results also show a negative correlation between vanity and vanity sizing. Indeed, when one's perceives her/himself negatively, (s)he has a good impression about vanity sizing, (meaning one is affected by the size label favoring a low digit), whereas one's with a positive self-esteem doesn't seem to be trouble by the size label, therefore does not embrace vanity sizing. These results are significant since they should result in practical implication.

Research limitation: First research of its kind and was done only in Montreal. It would gain to be extended to other geographic areas and to a larger scale including people of diverse age groups, ethnicities, etc.

Practical implication: Literature shows that a commercial practice such as vanity sizing is a marketing tool, but our results show it also has "benefits" on people with low self-esteem. On the other hand literature shows that vanity sizing has an economic impact and give rise to costly returns.

Therefore the apparel industry may want to rethink these commercial practices in regards to sizing in a way it benefits all parties.

Originality and value: For the first time we are able to validate the prominence of the size label effect on self-esteem, related to body shape and perception [vanity].

Key words: 3D body scan, perception, self-esteem, vanity, body cathexis,

\section{Introduction}

The purpose of this research is to investigate how people perceived themselves when comparing themselves to the ideal body image and 3D image as well as their feeling toward size label attached to garments. The following paper will unfold according to the following: reviews of the literature with regards to self-esteem, sizing and vanity sizing, followed by the effect of vanity sizing on self-esteem. The following section will briefly provide the hypothesis. The third section presents the methodology and the fourth section reveals the results of the study. Finally, we discuss the main findings, implications, limitations and areas for future research. 


\section{Literature}

\section{Self-Esteem}

Body image refers to how a person perceives their body or how they think other people perceive their body. Thus, body image is related to several aspects of an individual, including psychological and somatic aspects, in addition to being heavily influenced by the social environment (Rice, 1995; Ledoux et al., 2002; Burke et al., 2010). Meanwhile, self-esteem is the manifestation of the sense of satisfaction that one feels in terms of the definition given to the concept of self (Beane and Lypka, 1986). More specifically, it is a value judgment arising from one's perception of their skills in various fields. Proponents of Jamesian concepts of self-theories suggest that dissatisfaction in a particular area has an impact on general self-esteem to the extent that the area is central to the definition of self of that individual (James, 1890). For example, if the focus on appearance and weight is greater among women (Miller and Halberstadt, 2005; Wardle, Haase and Steptoe, 2006), we could assume that their level of satisfaction related to body image has a much greater impact on their general selfesteem than what could be observed in men (Tiggemann, 2005). Satisfaction regarding body image can be conceptualized multi-dimensionally. Thus, satisfaction or dissatisfaction regarding body image includes such notions as one's appraisal of appearance or weight (Mendelson et al., 1996), or the emphasis one puts on their general appearance or their satisfaction regarding specific body parts (Penkal and Kurdek, 2007). Lastly, several psychological factors are associated with dissatisfaction towards body image such as low self-esteem, depression, anxiety or having a negative perception of one's health (Pastore et al., 1996, Ledoux et al., 2002; Levine and Smolak, 2002).

\section{Apparel and Vanity Sizing}

Body images, fitness and the image of "thinness" is a huge factor that women have to deal with constantly in today's society, which has an everlasting pursue of beauty. In a day and time where "Consumer Behavior is defined as how individuals or groups select, purchase, use, or dispose of products as well as the needs and wants that motivate these behaviors" (Moriarty et al., 2009, p. 131) and where the fashion retail (cosmetics and apparels) is a billion dollar industry, vanity and vanity sizing became important attributes to increasing sales in clothing retail stores. Therefore, apparel companies can only satisfy those needs to the extent that they clearly understand their customers. Many clothing retailers understand their female consumer's wants and highly emphasize vanity revamping and introducing new clothing sizes in their merchandise across the board. This helps alter their customer's perception about themselves and clothing sizing. Thus, introducing a new size refers to what is so called "vanity sizing".

Vanity sizing refers to the practice of altering measurement specifications for garments to enable consumers to fit into smaller sizes (Alexander, Connel and Presly, 2005). In other words, vanity sizing is a strategy that manufacturers use to put smaller size numbers on clothes' labels (Aydinogly and Krishna 2012). Research has shown that vanity sizing has an impact on the consumer experience. When a consumer fits into a garment labeled smaller than their actual size, it leads to positive selfrelated mental imagery, positive attitude towards the product, and a more favorable consumer appearance (Aydinogly and Krishna 2012). On the other hand, a larger than expected size has the power to generate negative impressions about the product item, the brand, and ultimately leads to a decrease in purchase intentions for that particular item (Hoegg et al., 2014).

Workman and Lee (2010) found that women concerned with physical vanity, vanity achievement and public self-consciousness oftentimes blame themselves instead of blaming manufacturers and retailers when a garment doesn't fit them. Although more and more research is showing the downside of vanity sizing, it is unclear whether such labels are likely to influence facets such as consumer selfesteem and purchase intentions (Grossman and Shapiro, 1988). In a recent interview Gribbin (2014) has stated that Gen $Y$ do not care as much about sizing contrary to the previous generation.

\section{Vanity Sizing and Self-Esteem}

Does vanity sizing have to do with a consumer's self-esteem? For Triffin (2014) the answer is yes. "Size is the latest way to evaluate self-worth" (Triffin, 20144). Many women today see clothing sizing as a defining factor in how they view themselves and in having positive body images. For many the smaller the size number that they can fit into, the happier they feel inside and are more likely to be excited to buy a product. "Contending on the notion that thinner is better for today's women exposed to idealized thin images constantly, we propose that vanity sizing is used as a means to generate positive self-related mental imagery, which in turn improves attitudes towards the product" (Aydinoğlu and Aradhna, 2012, pp. 565). For some researchers (unpublished paper yet) this situation is worse for plus size teenagers. According to their preliminary results, sizing has a crucial impact on these teens' self-esteem. Tapping into this psychology, retailers see the amount of power vanity sizing has and the 
affect it has on consumers. Consequently, the evolution of clothing size like "6", "4", or "2" have downsized, hitting the point of now "triple zero" at J.Crew in their 2014 collections, and not to mention all the "extra, extra small" size labels (Faust, 2014). Consumers are thriving off of the new labeling of smaller garments, especially those that have low self-esteem. Smaller garments significantly impact their self-confidence and help promote positive mental imagery. Hence, "differing results for high and low self-esteem customers are consisted with compensatory self-enhancement theory whereby low self-esteem customers need that extra lift in self-image and may get it from a product lift" (Aydinoğlu and Aradhna, 2012, pp. 569). Therefore, it is right to say that sizing does have an indirect effect on one's self-esteem, and even more on someone with low self-esteem.

\section{H1: Someone with low self-esteem is definitely affected by sizing.}

These findings should suggest if vanity sizing should continue, variability in sizing garments would also continue to increase. This also may lead to low self-esteem, especially for those with a young, rounded figure. Therefore, one goal of the present investigation is to assess whether vanity sizing has a negative or positive impact on Gen $Y$ self-esteem and if the consumer experience affects purchases of fashion goods.

\section{Methodology}

A questionnaire was put together based on the literature. In one part, the self-esteem scale of Rosenberg (1965) was used to evaluate participant's self-esteem. Self-reported figures were also used to compare validity and reliability from the sets of nine illustrations of silhouettes, (Thompson and Gray, 1995) as well as the weight and average figures based on the National Center for Health Statistics (2004). In addition, questions were developed for appreciation of sizing and to evaluate sensibility to vanity sizing.

Participants were recruited among the Montreal Fashion and Design Festival public. The Fashion and Design Festival was held during the month of August 2014. Participants were asked to complete the online questionnaire (on a tablet) live at the booth. The data was collected and transferred immediately to a server. A group of well-trained recruiters were there not only to recruit but also to assist participants when needed and to make sure all the data was correctly transferred.

The questionnaire also collected data about body image and psychosocial experience, buying habits in relation to clothing, and basic demographic, socio-cultural and psychographic information. In addition to the data, height, weight and waist measurements were taken. Participants were measured using a height gage, a mechanical scale and a measuring tape by a group of well-trained recruiters. Participants were also scanned with a $[T C]^{2} 3 D$ body scanner. Each participant wore their own underwear. Almost 350 participants completed the questionnaire and were measured.

\section{Scales used}

The self-esteem scale used was Rosenberg's, (1965), which was adopted in its entirety to measure global self-esteem. It is an additive scale comprising 10 items in which the respondent receives a score between 1 and 4 for each item, depending on their choice of answers. The sum of the scores is established for each respondent and corresponds to a total score between 10 and 40 . The higher the score, the higher the respondent's level of self-esteem. This scale measures the overall perception of the individual's own worth.

To assess dissatisfaction towards one's figure, two sets of self-reported figures are used randomly to compare their validity and reliability in the sampled population. One of the sets comprises nine illustrations of silhouettes (Thompson and Gray, 1995) ranging from very thin to very corpulent for each gender. The other set tested in this study is the BIAS-BD of Gardner, Jappe and Gardner (2009), which illustrates 17 male and 17 female silhouettes. These figures are based on the most recent data from the National Center for Health Statistics (2004) regarding the weight and average size of an American man and woman. Based on this information, photos were taken of individuals who met the criteria precisely in order to create silhouettes of their bodies. In the case of both scales, respondents were initially asked to select the silhouette that best matched their current appearance and then to select the silhouette they would most like to resemble. 


\section{Results}

Our final sample size was 335 participants. Out of the data base 5 participants were removed because they provided missing information that is crucial to the survey, such as no gender or one wrote being 1 year old. At the end, the database compromised 330 participants' responses.

As for the demographic, the majority of the participants were as females as expected under the age of 40 years old. Less than 100 males took the survey with the age range of 16 to 56 years old.

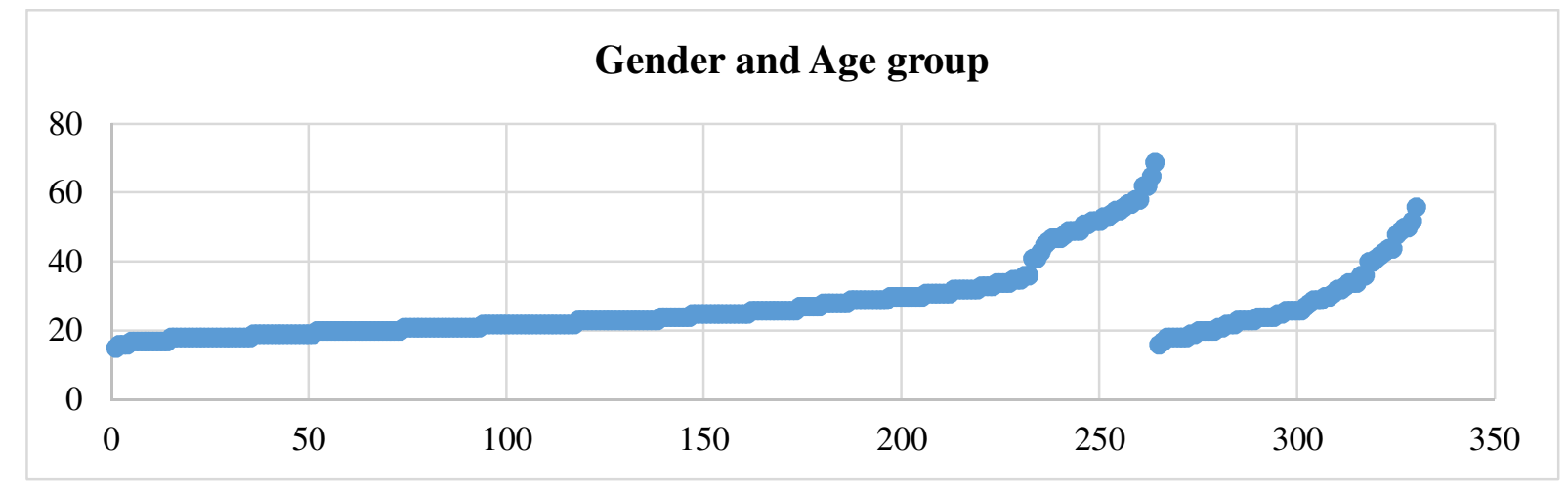

Table \#1. Gender and Age group of the participants.

As shown in the figure below, the vast majority of our respondents were white Caucasian females.

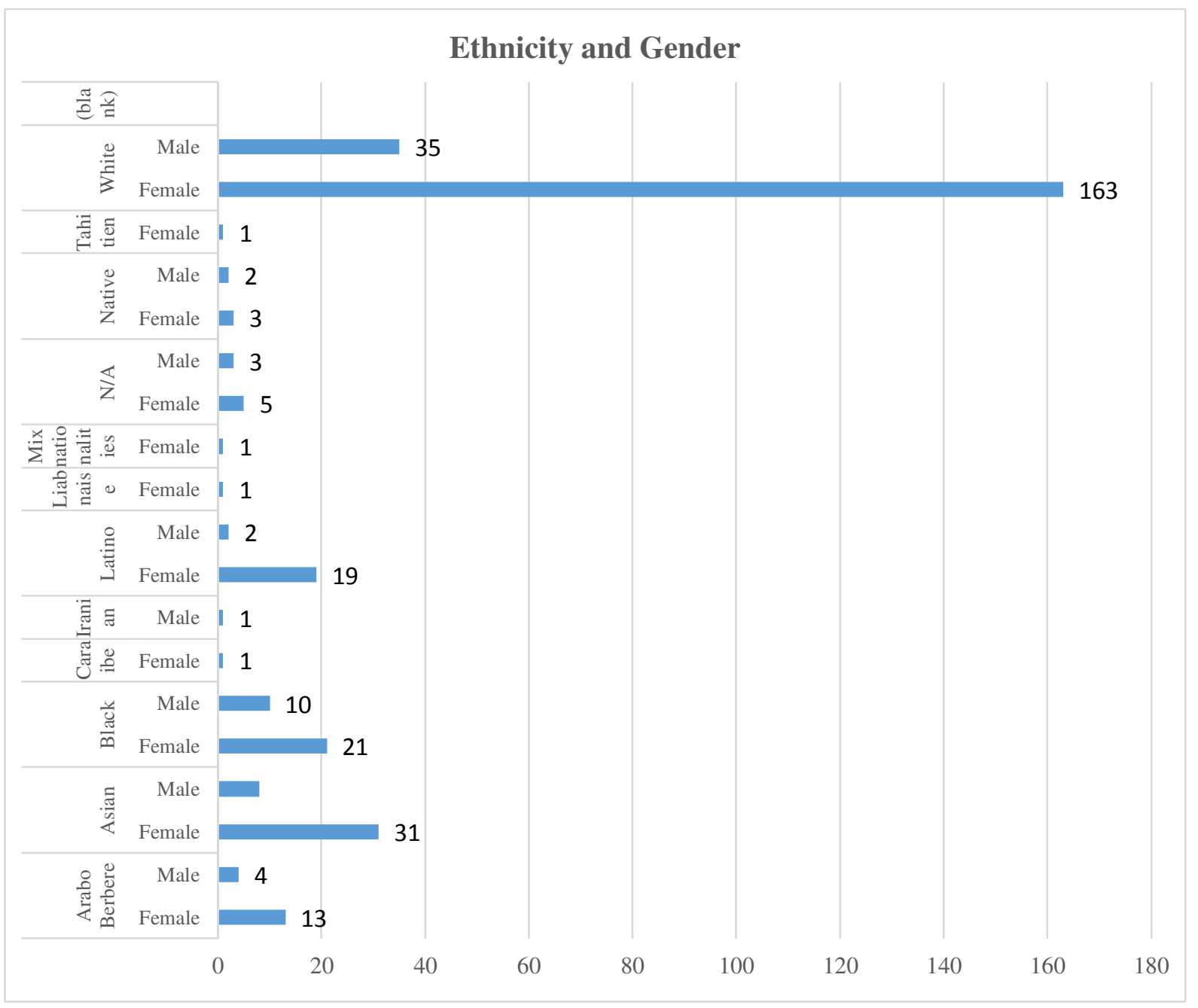

Table \#2. Ethnicity and Gender of the participants. According to our results, people spend between less than $\$ 50$ to $\$ 200$ per month for apparel. All together, it seems that most of our participants try them on before purchasing (Table \#3). However, they would usually not purchase it if they can't try it on (Table \#3). In addition, 33\% of our participants mentioned they take a picture of themselves, called a "selfie" and share with their peers before purchasing an item. 


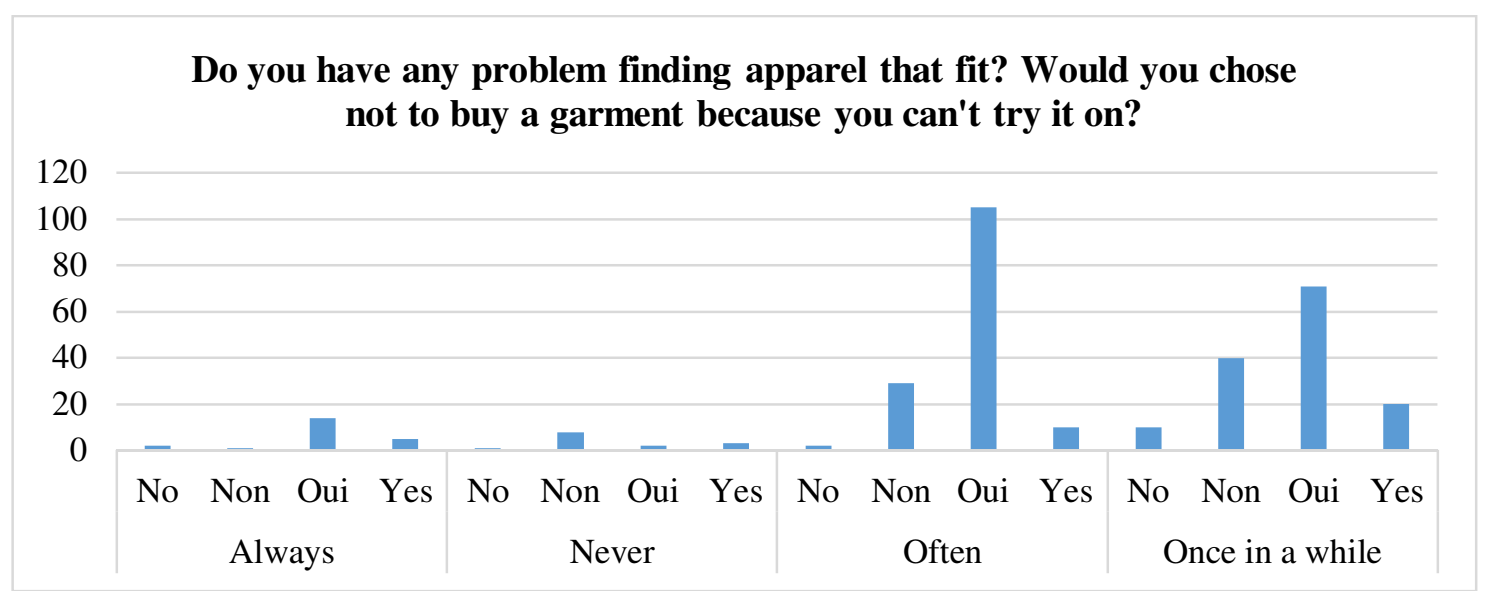

Table \#3. Do participants try on apparel a priori since they do not know the fit and would they not purchase a garment because they do not know if it will fit?

Generally speaking, it seems that as women get older, their self-esteem is lowered.

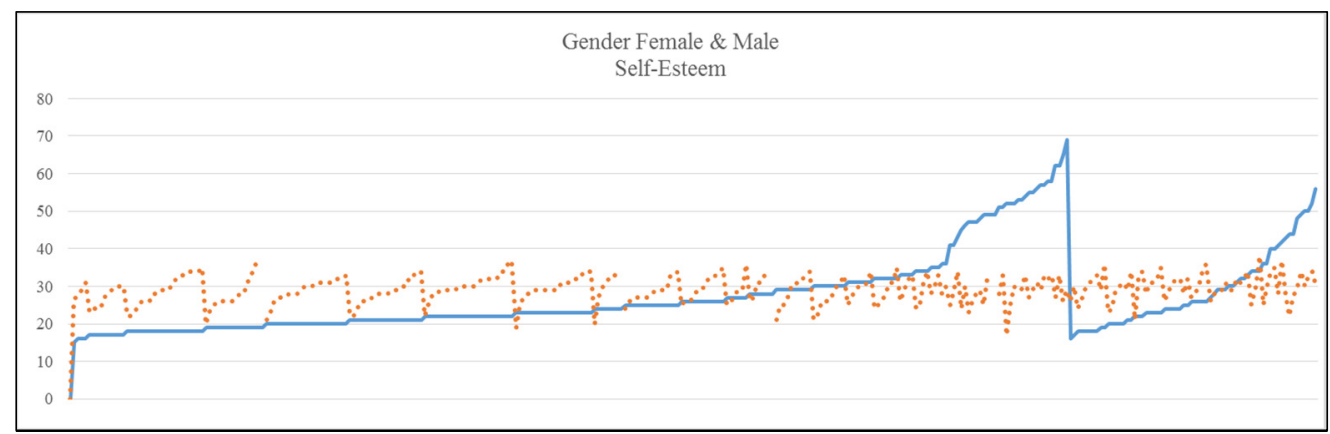

Table \#4 Female and Male according to their age and their self-esteem on a scale of 40 points.

The results of our vanity sizing survey were pretty straightforward and similar to other research results on vanity sizing and its links to self-esteem. Our results show us that the majority of our participants had positive self-views and were unaffected by clothing sizes. On the other hand, people with low self-esteem were affected by the size on the label which validate our hypothesis. Ultimately, we can conclude that when it comes to having high self-esteem, vanity sizing doesn't affect how one views themselves, nor does it create positive self-imagery. It's the complete opposite, which is indifference. People with high self-esteem do not really care what a label sizes insinuates about body sizes because their self-worth and positive imagery stem from other places and not from their waist size. It's accurate to say most of our participants were young females with a healthy weight and size and were "naïve" about the practice of vanity sizing. They also didn't consider vanity sizing a factor when trying on and buying clothes because of their relatively smaller sizes and high self-esteem.

\section{Managerial implications}

Investigating the impact of vanity sizing on the consumer self-esteem and experience in fashion has significant theoretical and managerial implications. Theoretically, it will contribute to the rather limited discussion that has emerged on vanity sizing. It will also assess whether vanity sizing differs with regards to generations and self-esteem. Managerially, it will give insight as to whether universal sizing is an appropriate strategy to reduce such effects and improve the consumer experience.

\section{Conclusion}

In short, the common practice of vanity sizing is here to stay. Research shows female consumers react positively to smaller than expected sizes. Also, researchers mentioned they "found a direct effect of vanity sizing on product attitudes for all consumers, regardless of self-esteem level, which lends credence to the common belief that vanity sizing works" (Aydinoglu 571).

Whether it's the ability to brag or the enhancement of self-perception due to buying a smaller size, there are reasons why some female and male consumers see vanity sizing as very appealing. Ultimately, "women want to measure up the 0 ideal" as stated by Triffin (2014). Therefore, smaller size labels speak volumes because it evokes positive thoughts that add to the effectiveness of vanity sizing. 


\section{Limitations}

This research was in its introductory phase and took place in Montreal, Canada. It was done during fashion week where most of the participants were fashion people. Lastly, it was an interesting sample of more than 300 participants, and the period for recruiting was very short and lasted only a few days. Lastly, most participants were white Caucasian females.

\section{References}

AYDINOGLU, N. Z., and ARADHNA K., (2012). "Imagining Thin: Why Vanity Sizing Works." Journal of Consumer Psychology Vol. 22 \#4, pp. 565-72.

BEANE, J. A. et R. P. LYPKA. (1986). Self-concept, self-esteem and the curriculum. New York, Teachers College Press, 262 pages.

BURKE, M., HEILAND, F.W. and NADLER, C.M.. (2010). "From "Overweight" to "About Right": Evidence of a Generational Shift in Body Weight Norms", Obesity, 18, pp. 1226-1234.

GARDNER R. M., JAPPE L.M. and GARDNER, L. (2009). "Development and Validation of a New Figural Drawing Scale for Body-Image Assessment: The BIAS-BD”, Journal of Clinical Psychology, Vol. $65 \# 1$, pp. 113-122.

GRIBBIN, E. (2014). Interview on WHYY, with FAUST, M-E. August 2014.

JAMES, W. (1890). The principles of psychology. New York, Henry Holt, 897 pages.

LEDOUX, M, MONGEAU L and RIVARD, M. (2002). "Poids et image corporelle", dans Enquête Sociale et de santé des enfants et adolescents québécois 1999. Québec, Institut de la statistique du Québec, Chapitre 14, pp. 311-344.

LEVINE, MP and SMOLAK, L. (2002). "Body image development in adolescence", in T. F. Cash and Pruzinsky, T. (eds.), Body Image. A Handbook of theory, research, and clinical Practice. New York, London, The Guilford Press, pp. 74-82.

MENDELSON, B.K., WHITE, D.R. and MENDELSON, M.J. (1996). "Self-esteem and body esteem: effects of gender, age, and weight", Journal of Applied Developmental, Psychology, Vol. 17 \#3, pp. 321-346.

MILLER, E. and HALBERSTADT, J. (2005). Media Consumption, Body Image and Thin Ideals in New Zealand Men and Women. New Zealand Journal of Psychology Vol. 34 \#3, pp. 189-195.

MORIARTY, S., MITCHELL, N. and WELLS, W. (2009). Advertising: Principles and Practices. 8th ed. N.Y.: Pearson Education National Center for Health Statistics. 2004. Mean body weight, height, and body mass index, United States 1960-2002. Advanced Data No 347, PHS 2005-1250 pp. 1-18.

PASTORE, D.R., FISHER, M. and FRIEDMAN, S.B. (1996). "Abnormalities in weight status, eating attitudes, and eating behaviors among urban high school students: correlations with selfesteem and anxiety", Journal of Adolescent Health, Vol. 18 \#5, pp.312-319

PENKAL, J.L. and KURDEK, L.A. (2007). "Gender and race differences in young adults' body dissatisfaction", Personality and Individual Differences, Vol. 43 \#8, pp. 2270-2281.

RICE, C. (1995). Meilleur départ. La promotion d'une image corporelle saine: un guide à l'intentiondes planificateurs de programmes. Centre ontarien d'information et de prévention, 81 pages.

ROSENBERG, M., SCHOOLER, C., SCHOENBACH, C. and ROSENBERG, F. (1995). "Global selfesteem and specific self-esteem: different concepts, different outcomes", American Sociological Review, Vol. 60 \#1, pp 141-156.

TRIFFIN, M. (2014). "The Insanity of Size 0." Cosmopolitan. N.Y., n.d. Web. 11 May 2014.

THOMPSON, M.A. and GRAY, J.J. (1995). "Development and validation of a new body-image assessment scale", Journal of Personality Assessment, Vol. 64 \#2, pp. 258-269.

TIGGEMANN, M. 2005. "Body dissatisfaction and adolescent self-esteem: prospective findings", Body Image, Vol. 2 \#2, pp. 129-135.

WARDLE J, HAASE, A.M. and STEPTOE, A. (2006). "Body image and weight control in young adults: international comparisons in university students from 22 countries", International Journal of Obesity Vol. 30, pp. 644-651. 